\title{
Rasgos culturales de los Chimbus y Guarangas en la provincia de Bolívar
}

Fecha de recepción : 03 de julio de 2019 • Fecha de aceptación: 4 de octubre de 2019 • Fecha de publicación: 13 de enero de 2020

\author{
Vicente Bolívar Guzmán Bárcenes \\ Universidad Estatal de Bolívar \\ vguzman@ueb.edu.ec \\ https://orcid.org/0000-0001-8038-9324 \\ Nancy Gloria Alvarado Ramos \\ Universidad Estatal de Bolívar \\ nancyalv_10@hotmail.com \\ https://orcid.org/0000-0002-0974-9347 \\ Erika Nataly Alvarado Ramos \\ Universidad Estatal de Bolívar \\ erik18nataly@gmail.com \\ https://orcid.org/0000-0002-0163-633X
}

\section{Resumen}

En el Ecuador, la cultura "Chimbo", se ubicó en el mismo sitio donde hoy se asienta la ciudad de San José Chimbo, se caracterizó por un amplio conocimiento de las técnicas de la agricultura, hilandería, alfarería y el pastoreo. Los rastros encontrados a lo largo de la investigación, muestran una cerámica de textura rústica y áspera, las vasijas llevan en el cuello una especie de anillos, producidos con un tubo de carrizo, con ojos en formas de pepa de café. Los "Guarangas", por su parte, tienen las mismas características que los Chimbos, además, sus lenguas, que eran una mezcla entre la barbacoa, cañarí y panzaleo (Guamán, 2018). Es decir, que la lengua kichwa, aparece posteriormente con las conquistas de los Incas y relaciones comerciales entre estos pueblos (Itier, 2015). 


\begin{abstract}
Chimbus culture was settled in the area where today is the city San José Chimbo, one of the cantons of the province of Bolívar in Ecuador. This culture was characterized by their widen knowledge on agriculture, weaving, pottery, and livestock. The remains found throughout my research show that the community used clay to make utensils with a little rustic texture; their rough vessels carry in their neck a kind of rings, made with a reed, with eyes in forms of coffee's pepas. The Wuarankas had the same Chimbos' characteristics; it is said that these peoples shared the same language- a mixture of barbacoa, cañari, and panzaleo. Consequently, the Kichwa language appeared during the commercial relationships among these and Peruvian peoples (Itier, 2015).
\end{abstract}

Keywords: Cultural traits, Chimbos, Wuarankas, traces, ancestors. 


\section{Introducción}

Los rasgos culturales dejados por Chimbus y Wuarankas, tienen en la actualidad una importante repercusión sociocultural, sus hallazgos exaltan y llenan de inquietudes a todo un público, pero detrás, existe un conjunto de conocimientos que permite detallar aspectos relevantes. Los rastros considerados como huella del comportamiento humano, permiten construir todo un proceso que ha creado el ser humano en el mundo en que vivimos y fundamentando el comportamiento, la minuciosidad y el profundo sentido de progresar es un punto de partida de estos pueblos. Sin embargo, no se ha comprobado de que exista un registro de investigaciones completas y los registros arqueológicos son limitados.

La primera referencia histórica a los Chimbus, aparece a partir de la descripción realizada por Cieza de León (1548) citado por Millones (2001) en donde se afirman que los Chimbus fueron Mitimaes llegados de Cajamarca, se cree que se asentaron desde el periodo formativo (35002000 aC.), ubicándose a lo largo de la costa y sierra bolivarense (yunga y chiri llacta) Yánez del Pozo (2003) sus actividades más importantes fueron la alfarería, pastoreo, hilandería y agricultura. Para aclarar, nuestra posición con respecto al origen de este pueblo estamos mucho más de acuerdo con (Itier, 2015) cuando afirman que los Chimbos fueron un pueblo originario. Las Ciencias Sociales, en especial la Arqueología, tienen la libertad de indagar y dar respuestas a muchas hipótesis sobre este tema, pero realmente los rastros dejados son los únicos testigos de la realidad. El presente texto está dirigido a reflexionar sobre los rasgos culturales de los rastros ancestrales encontrados entre los cantones de Chimbo y Guaranda, se realiza una investigación literaria, se obtuvo limitaciones en base a las pocas investigaciones realizadas, no obstante, se encontró información relevante e importante para el desarrollo del presente estudio.

Durante el desarrollo de esta investigación, los métodos empleados estuvieron enmarcados por el analítico-sintético, histórico-comparativo, hipotético-deductivo son métodos teóricos de la investigación, fue necesario utilizar herramientas de zapa, cámara fotográfica, brochas para evitar la fragmentación o fricciones inadecuadas al momento de su rescate; las técnicas aplicadas: la observación directa, la entrevista a los propietarios de sus terrenos y el muestreo.

\section{Desarrollo}

\section{Los Chimbus y Guarangas}

El desarrollo cultural de la provincia de Bolívar se fundamenta en sus bases ancestrales estipuladas por las tribus de la provincia, para esto se revisa la historia del cantón Guaranda en base a lo estipulado en la casa de la cultura ecuatoriana. El documento registrado en la casa de la cultura trata de crear interés en quienes les gusta la historia, la antropología, sociología, arqueología, en conclusión, las ciencias sociales en toda su extensión, la única ciencia que da respuesta o interpretaciones a los hallazgos de las diferentes culturas ancestrales asentadas alrededor del mundo y especialmente de los Chimbos y Warankas en la provincia Bolívar (Casa de la Cultura Ecuatoriana, 1956). 
Es necesario aclarar que las bases de los análisis e interpretaciones que se hace son a partir de estudios comparativos con textos informativos de historiadores y trabajos realizados por algunos arqueólogos nacionales e internacionales. La idea principal es presentar los orígenes de estos hallazgos y dejar abierto el debate para que futuras investigaciones, aporten sobre la base del conocimiento adquirido en su experiencia profesional sobre la temática

Por otra parte, y teniendo en cuenta que se está hablando de piezas que fueron rescatadas en diferentes circunstancias, sobre las cuales no existen reportes técnicos, no se puede ser objetivos en el análisis sobre la ubicación y espacios exactos. Costales (1956) describe su pasión hacia el conocimiento de la arqueología, pero desde el punto de vista especializado no contaba con las herramientas necesarias para actuar en correspondencia con las exigencias metodológicas en este tipo de investigación exige, al no contar con ello no se puede develar o confirmar todas las hipótesis que surgen, por lo que, las ideas se quedan en el campo de la reflexión y la especulación, esperando con este texto, reiterar, motivar a los conocedores y apasionados de estas ciencias, se unan y conformen un grupo de trabajo en esta provincia rica en rastros ancestrales, sobre los que poco se habla y que dediquen con seriedad tiempo y presupuesto a proyectos de investigación de este tipo.

Según Idrovo (1994) numerosas acepciones se han dado al significado de la palabra Chimbo. Así, La Condamine (1986) Le hace derivar de Chimpani - Chimbani o "pasar el rio", Humboldt, sostiene que el término proviene de Chimpu, o hilos de colores. Por su parte, (Calvo, 1995) señala que existen cuatro significados asociados a la lengua quechua, estos son: arruga, vestido y tejido, señal para animales, e insignia o distintivo de lana.

Los Chimbos fueron un pueblo originario, floreciente y caracterizado por el desarrollo de la alfarería, integraron antes de la conquista un conglomerado de asentamientos étnicos de gran importancia, del cual formaron parte las parcialidades de Guarangas, Tomabelas, Azancotos, Chapacotos, Chillanes, Tumbucos, entre otros (Yánez del Pozo, 2003). Los Chimbus conformaron un "gran estado", muy similar a lo que fue el primitivo Reino de Quito, y mantuvieron una guerra perpetua contra los Huancavilcas y con los Régulos de Cañar. Los Chimbus tenían conformada una nación valiente y batalladora, por lo cual los Puruháes se aliaban con ellos, con la seguridad de su lealtad en la lucha contra los Huancavilcas y los Cañarís.

Según González Suárez (1890) los Chimbus ocupaban desde la Cordillera de los Andes, (Chiri llacta) hasta la costa (yunga) y se extendían hasta Babahoyo, es evidente, su existencia en estos lugares, por los rastros y fragmentos de cerámica encontradas a lo largo de estos sectores. Al respecto, Idrovo (1994) manifiesta que, durante el período de ocupación incaica, se presume que los chimbos habrían ocupado todo el espacio occidental del Chimborazo, el valle de Guaranda y las estribaciones occidentales de la Cordillera hasta llegar al Subtrópico,

El territorio de los Chimbos estaba dividido en nueve kuracazgos, cada uno con sus respectivos ayllus, estos son: kuracazgo de los Chimbus, de Chimas, de los Guarangas, de Guanujo, de Shimiatuc, de Asancoto, de los Chapacotos, de Chillán y de Pallatanga De manera que los Chimbos constituían como una agrupación de kacicazgos que limitaban al norte con parte de los Puruháes y Panzaleos, al Sur con los Kañaris, los Killakos y los kuracazgos de los Lausis y 
Tiquizambis, al Oriente con la nación de los Puruháes, y al Occidente con los Huancahuilcas y Barbacoas (Costales Sarmiento, 1956; Idrovo, 1994).

Según Costales Sarmiento (1956) los kurazcazgos estaban ordenados alrededor de un kuracazgo principal, que era el de los Chimbus o Chimbo Mediano. Sin embargo, de acuerdo a (Calvo, 1995) no parece haber existido un poder centralizado, es decir, un kuracazgo con grupos subalternos, Ramón (1993) señala la existencia de varios niveles de organización que van desde las formaciones sociales de tipo tribal hasta confederaciones, todas unidas por el intercambio.

El nombre del kuracazgo de los Guarangas (o Waranka en quichua) proviene de "la voz quichua GUARANGA=MIL número cardinal, a ello se puede asociar lo que algunos historiadores aseguran, que se debió este nombre al ÀRBOL DE GUARANGO, donde solían tener consejo los indios de esta comarca, posiblemente este consejo estaba integrado por mil caciques de ayllos"(Costales, 1954, p 11), En este caso se leería Guaranga, como el "sitio del árbol", Costales (1954) añade la siguiente interpretación: Guaranga viene de la voz Panzalca que significa poblado, y Auga o Auca que significa gavilán, en kichwa quiteño y cusqueño, respectivamente, es decir, se entiende al término Guaranga como "Poblado del gavilán".

A su vez, el kuracazgo de los Guarangas estuvo compuesto por quince ayllus, estos son: Chitahua, Guandul, Cargua, Cuasgual, Alacu- Huela, Oshosho, Juibine, Illahalo, Guambo, Cusumuncho, Guangoliquín, Chunguto, Mondogueta, Silagoto y Salaleo. Se cree que los primeros habitantes de este sector, fueron mitimaes que llegaron de Cajamarca, desde Los Andes al norte del Perú (Paz Maldonado, 1889; Costales y Costales, 2002; Costales, 1954; Jijón y Caamaño, 1951). En adición, de acuerdo a Jijón y Caamaño (1951) se presume que la cultura Guaranga, tenía gran relación con las culturas Guangalas, (100 AC. 750 DC.), Manteño (900 DC. 1500 DC.) y Atacames de la costa (700 - $850 \mathrm{DC})$, esto dados los rastros hallados con los ojos en forma de pepa de café, característicos de estas culturas (Jijón y Caamaño, 1951).

En lo que respecta a la economía de los Chimbos, Idrovo (1994) destaca la variada composición de pisos ecológicos, los cuales facilitaban la obtención de productos derivados la agricultura, la ganadería, la explotación de cobre, oro y sal, y el intercambio. Así, su economía estaba sostenida por: restos de terracería, canalización antigua y campos cultivados, localizados en todos los pisos del territorio, y caracterizados por una combinación de terrazas verticales con horizontales, por cortes de terreno bajos y elevados, dado su potencial agrícola, dentro del territorio se obtenían tubérculos y quinua (pisos de altura), maíz, legumbres, frutas, algodón, coca, yuca, la ganadería era además una actividad realizada de forma constante a las faldas del Chimborazo; se destaca la presencia de restos de antiguos corrales; y, la minería, de manera que se dio una explotación temprana de oro y cobre.

De esta forma, la verticalidad ecológica y la diversidad natural permitieron la formación de un sistema de intercambio complejo de productos, en donde se destaca la presencia del comercio a través de los llamados "mindalaes".

Además, existieron actividades artesanales como la producción textil y alfarera, éstas se daban en un circuito inter - ayllus y a través del comercio de corta y larga distancia entre pueblos de la 
Sierra y de la Costa, posibilitado a través de una red de caminos que cruzaban la zona de Norte a Sur y de Este a Oeste.

En cuanto a su aspecto, Vásquez de Espinoza (1948) manifiesta "traen aquello como cerquillo a modo de los italianos, visten sus camisetas de lana con abertura por detrás y por delante; al traje turquesco, sin mangas, son de muchas maneras ellos están de ordinario en cloquillas hilando de lana con sus ruecas".

Acerca de la relación con otras etnias, se señala al territorio Chimbo como abierto a la permanencia de colonias de etnias variadas, hecho que obedece probablemente a efectos del comercio interregional, el intercambio cultural, tecnológico y económico. De forma que (Calvo, 1995) los describe como un enclave multiétnico formado por gente de Sigcho, Latacunga, Mulahaló, Panzaleo y Puruhá.

Respecto a la similitud de los Chimbos con los Puruhaés, (Millones, 2001) expresa:

"En la comarca de Quito, no muy lejos de Tomebamba está una provincia, que ha por nombre Chumbo (...) Hay en la comarca de estos pueblos aposentos principales como en los pasados, y sirvieron y obedecieron a los Ingas señores suyos, y hablaban la lengua general que se mandó por ellos que se usase en todas partes (...) Tienen las costumbres como los que arriba he dicho. Y son semejantes a ellos en las religiones. Adoran por dios al Sol, y a otros dioses que ellos tienen o tenían"

Siguiendo este mismo orden de ideas, Paz Maldonado (1889) indica que existe una identidad en las prácticas con los Puruháes, en donde el Chimborazo representó una deidad altamente valorada, además del culto a fuentes de agua y elementos de la naturaleza como el sol y la veneración de Apu Catequil o Atagujo traído por los mitmaq'cuna.

Asimismo, se registra al puruhá como el idioma propio de los Chimbos, y al quechua impuesto por los incas, a partir del siglo XVI, de forma similar la arquitectura existente en el área rural consiste en una fiel reproducción de los tipos constructivos de las casas de los Puruháes (Paz Maldonado, 1889; Jijón y Caamaño, 1951). Luego, el elemento más importante de la identidad cultural de los Chimbos está en su cerámica. De acuerdo a (Calvo, 1995), en el Museo de la Provincia de Bolívar junto con la extensa cantidad de materiales culturales -en particular cerámica- pertenecientes a la alfarería Puruhá y Panzaleo, identificada con distintos momentos de sus propias evoluciones y mezclada con metalurgia y conchas marinas quizá provenientes de centros de Milagro, Quevedo y Bahía, se encuentra la cerámica Chimbo, la cual tiene un corte parecido a la Puruhá e incorpora rasgos de identidad propia.

Así, el estilo Chimbo se ubica en el Período de Integración (500 - 1500 dC), y consta principalmente de las siguientes formas: Cántaros, también llamados en el idioma quichua "pondos" o "pundu", con tamaños que van desde los $20 \mathrm{~cm}$ hasta los $70 \mathrm{~cm}$ de altura, y que fueron utilizados para actividades como el almacenaje y el transporte de líquidos y sólidos, algunos no llevan atributo a excepción del engobe -el cual suele ser de color rojo claro con líneas carentes de pintura- y son de cuerpos alargados y base cónica, mientras otros constan de 
una decoración simple con incisiones que pueden ser geométricas o antropomorfas; Ollas, son polípodas o de cuerpos esféricos y de base redonda, las cuales tienen una capa de hollín en su interior puesto que sirvieron para la cocción de los alimentos; Cuencos, por su forma -hondos y bajos- se presumen sirvieron para el servicio de alimentos crudos y cocidos al igual que los platos; Compoteras, de base mediana $(10 \mathrm{~cm})$ y baja altura $(5 \mathrm{~cm})$ decoradas en el fondo del plato con figuras geométricas hechas con incisiones de exciso; Vasos altos o timbales, cucharas, pulidores de cerámica, fusaiolas, y finalmente, las figurillas (Echeverría, 1981; Idrovo, 1994).

Por su parte (Arellano, 1992), por medio de un análisis de carácter tipológico regional de la cerámica para la zona de Sierra de la cuenca del Río Chimbo encuentra un total de 44 sitios ubicados en las terrazas dispuestas longitudinalmente a lo largo de la cuenca. Dentro de la clasificación de los sitios se reconoce material cultural compuesto principalmente por cerámica, perteneciente a la fase tardía del Período de Integración (1000-1400 d.C.) distribuidas a lo largo del margen occidental de la cuenca del río Chimbo.

De forma que se dispone de un inventario de 2383 elementos de cerámica fragmentados, de los cuales el 59,93\% se ubicaron en la región central de la cuenca. Posteriormente, mediante un análisis tipológico se ubicó a la cerámica encontrada en la tradición Chimbo - Tomabela y se reconoció dos tipos: Decorados y No Decorados, caracterizados por una pasta compacta, un antiplástico de arena mediana, y un acabo exterior con un engobe pulido de color marrón claro. Se reconocieron además tres clases, estas son: vasijas, vasijas globulares trípodes y cuencos. Dentro de las vasijas se encontró una subclase conformada por vasijas ovoidales o cántaros decorados con un conjunto de impresiones circulares que seguían un patrón geométrico, aspecto relevante de la cultura Chimbo, además de otra subclase conformada por vasijas globulares tipo ollas, con bordes con un diámetro de boca inferior al de su cuerpo. Así también se encontraron cuencos simples -vasijas con bordes directos, base plana o convexa, acabado con engobe o alisado- y compuestos -comparten las mismas características con los simples a excepción de una base o soporte anular de una altura variable entre 0,7 a 2,5 cm.

Luego, Idrovo (1994) mediante una serie de excavaciones que tuvo una duración de 9 días en Puri Cocha, y de la cual formaron parte varios miembros de la Escuela de Educación y Cultura Andina de la Universidad Estatal de Bolívar, encontraron depósitos circulares de cerámica fragmentada colocada de "forma intencional", lo cual podría considerarse un indicio de una práctica ceremonial en la cual se consumían alimentos para posteriormente romper las piezas y entregarlas como ofrenda a la Pacha Mama, divinidad presente en la mayor parte de los cultos andinos. En Vinchoa se encontró una dispersión de entierros, hecho que podría asociarse a un patrón de asentamientos disperso, en donde los poblados no constituían centros de concentración de viviendas sino más bien estructuras distantes las unas de las otras ubicadas dentro de los límites de los ayllus, además se encontraron una serie de tumbas las cuales mantienen una modalidad pozo y cámara decorada con ciertos elementos distintivos como una tapa de piedra plana y detalles de conchas marinas. Luego, en Tagma se encontró materiales considerados extraños al estilo Chimbo, lo cual, desde la perspectiva de enclave multiétnico, anteriormente mencionada, podría ser un símil a la alfarería de los Panzaleos y Puruháes dispersa por todo el Ecuador por efectos del comercio.

Las vasijas eran rústicas, elaborada con un barro grueso y tosco y aunque tiene una figura 
antropomorfa, se puede tomar como elemento de interpretación a la mujer. Vemos en su canutado en los cuellos de la vasija ojos y boca en forma de grano de café; por su posición hacia abajo se parece más la mirada de una mujer dedicada a la productividad y la fertilidad. Esta característica está presente además en otras culturas; en la cultura Virú o Gallinazo ubicada al norte del Perú, (100 aC-500 dC) así como en la decoración de las vasijas araucanas - pueblo Mapuche del Sur de Chile (1200 - 400 dC), según Berdichewsky, y de Guzmán (1971), se encuentran además en los cacicazgos prehispánicos de Guabas en el Valle del Cauca (700- 300 dC) y en la cultura Muisa en el departamento de Santander, Colombia (Siglo VI aC) (Vainfas, 1996). Esta investigación trata de hacer una breve comparación de los rastros rescatados entre las dos culturas y concluir con sus semejanzas y diferencias, para al fin deducir los rasgos culturales que unían a estos pueblos ancestrales.

Es importante resaltar que este documento no es netamente arqueológico, más bien se caracteriza por ser descriptivo e informativo. Según el Instituto Nacional de Patrimonio Cultural del Ecuador, regentado por la Licenciada Carmen Rosa Ponce Leiva, representante legal de esta institución. En agosto 24 del 2004, certifica que las piezas arqueológicas de los Chimbus y Guarangas, tienen una filiación cultural a los Puruháes, cultura que se desarrolló en el periodo de integración (1200 DC. A 1500DC), geográficamente se puede ubicar en la región interandina del Ecuador de la provincia de Bolívar.

Las características son únicas de esta cultura, la forma de sus vasijas, tienen una boca ovalada angosta con cuello adornado con collares canuteados y la parte de su cuerpo es elíptica que termina en punta, algunas presentan características antropomorfas, zoomorfas y con engobe simple, en conclusión, podemos decir que nuestra cultura Guaranga tenía amplias relaciones con los demás pueblos aborígenes tanto de la sierra como de la costa (Vainfas, 1996).

La ocupación de estos pueblos se caracterizó por la agro alfarería o cerámica, se cree que nada de lo elaborado era autóctono, sino más bien da a entender, que existía una amplia difusión de rasgos culturales llevados y traídos probablemente por el trueque o los intercambios culturales; dentro de la cerámica confeccionaban, ollas trípodes, vasijas, compoteras, botellas con asas, cuencos, cantaros, antropomorfas y zoomorfas y una gran variedad de figurinas de uso personal y religioso. Estas figurinas lo decoraban con la conocida técnica del canuteado, técnica que es auténtica de los Chimbus, consiste en hacer una serie de círculos alrededor de los cuellos de las vasijas, por la necesidad de moler el maíz, fabricaron grandes piedras llamadas metates o mama rumi y la guagua rumi, o mano que servían para la molienda de la harina de maíz, la sal en grano y el ají. Este último, fue uno de los elementos indispensables en la alimentación diaria (Robayo, 2013).

Acerca de la Época Aborigen, a causa de la carencia de investigaciones arqueológicas y etnohistóricas, en el momento actual, es poco todavía lo que se puede afirmar. La tradición quiteña recogida por Vainfas (1996) menciona que, una vez conquistada la región Cañar, Túpac Yupanqui ordenó fabricar fortalezas y aposentos en Azuay, Pomallacta y Tiocaxas, con el objeto de defender la nueva frontera contra los ataques de los "Puruhaes y Chimbos, que eran gentes que andaban alteradas", además de otros pueblos que todavía no habían aceptado el dominio incaico. Con posterioridad a esta incursión, que parece terminó con la conquista de Quito, Túpac Yupanqui 
retornó por los Llanos (la Costa) al Cuzco: durante este viaje exploró "las Provincias interpuestas de Quito hasta la mar, creyendo fueran de tanta sustancia como las ya vistas y conquistadas, y con tal presupuesto entró por la Provincia de los Chimbos, y rompiendo inaccesibles asperezas llegó a la Provincia de los Guancavilcas." (Cabello Valboa, 1951: 322), referencia documental clara a la índole de la región de Chimbo, como uno de los pasos obligados entre la Sierra y la Costa. Por comparación con las regiones circundantes, se puede deducir que, en vísperas de la invasión incaica, la provincia de los Chimbos estaba conformada por un conglomerado de pequeños cacicazgos, a nivel local, pero no existe todavía argumento alguno para dilucidar si esa forma de organización política había llegado al nivel de una jefatura o señorío étnico, es decir, si existió entonces un curaca mayor a nivel regional, al que estaban supeditados todos los caciques locales. El alcance actual de las investigaciones tampoco posibilita determinar cuáles fueron las parcialidades de los Chimbos y hasta dónde se extendía su territorio 37 y su área de influjo. Al respecto, si se tiene en cuenta que durante la Colonia los cacicazgos de Guanujo y Guaranda, así como los ayllus subordinados de Simiátug y Tomabela, estuvieron regidos por miembros de la familia Cando Pilamunga, se podría poner, como hipótesis, la existencia de alguna relación entre las autoridades étnicas de la zona superior de la cuenca del Chimbo (Guaranda, Guanujo, Salinas, Simiátug) con el cacicazgo de Pilahuín (altos de Ambato) y parcialidades a él adjuntas (Costales, 1954). La comprobación de esta hipótesis pondría en evidencia la constitución de la cuenca del Chimbo como una región multiétnica, cuya sección superior habría estado habitada por comunidades indígenas emparentadas con las suroccidentales de la hoya de Ambato, mientras que la zona media y baja del río Chimbo habría sido el habitat de los Chimbos propiamente dichos, pueblos a los que habría que añadir la colonia multiétnica de explotadores (Camayos) de las Salinas de Tomabela y posteriormente los numerosos grupos de mitimaes implantados allí por los Incas (Moreno Yánez, 1981).

\section{Conclusiones.}

Se reflexiono sobre el rico patrimonio en rastros ancestrales que tiene la provincia de Bolívar, el cual se determina que es un legado poco estudiado y valorado, sin considerar que la investigación puede servir para afianzar la identidad de los pobladores de esta región, las evidencias materiales encontradas, fruto de muchos años de búsqueda son un testimonio fehaciente del habitad de estos pueblos nativos que supieron adaptase y modificar el medio, para establecer una agricultura y alfarería desarrollada propia de sociedades de alto nivel de desarrollo de sus fuerzas productivas.

Los pueblos, Chimbus y Guarangas, se establecieron en estos territorios y aquí desarrollaron la alfarería, hilandería y la agricultura como elemento básico para su supervivencia, también un avance considerable fue la domesticación de los animales, lo que ayudó a mejorar su condición de vida, el hombre nunca dejó de ser cazador y con los animales en cautiverio le facilitó cultivar la tierra para proveerse de alimentos seguros, para una población que iba en acelerado aumento.

La evolución del hombre es un proceso que no se pude detener, por tal razón, se infiere que fue la razón para que en los pueblos Chimbus y Guarangas surga la necesidad de contar con utensilios para la cocción, transporte y preservación de alimentos, es aquí en donde aparece la elaboración 
de la cerámica, que expuestos a altas temperaturas alcanzaron consistencia y funcionalidad, es por eso que a estas culturas se les conoce como agro-alfareras, estas piezas fueron elaboradas a mano y luego les pulían para darles su acabado perfecto, posterior a ello lo agregaban pigmentos y adornos con figuras de hombres, mujeres, animales, dioses, frutas, etc.

Los hallazgos de estas piezas, permitieron conocer las costumbres y forma de vida de nuestros pueblos originarios, asombra la hilandería, materia prima que la obtenían de la lana de las llamas y alpacas, el algodón que fue transportado de la costa (yunga) de igual forma aparece la vivienda, construidas de manera rustica sobre el suelo, cubierta con paja, para evitar el frio reinante.

A las culturas Chimbus y Guarangas, pertenecen los rastros encontrados en varios lugares del cantón Chimbo y de la ciudad de Guaranda, en la provincia Bolívar, los descubrimientos se hacen mayores cuando los campesinos con sus aperos de labranza descubren tumbas o nichos y otros elementos propios de la superestructura de estas comunidades. Por medio de las investigaciones de campo se ha podido rescatar piezas de cerámica de un valor excepcional, lo que puede permitir un futuro convenio de trabajos entre investigadores y la Universidad Estatal de la Provincia de Bolívar.

\section{Recomendaciones}

Por considerar que las piezas encontradas durante los trabajos de campo son de un altísimo valor cultural para demostrar el rico patrimonio material de la Provincia de Bolívar, las autoridades seccionales deben interesarse en apoyar a las personas que buscan rescatar estos rastros y poner a buen recaudo, ubicarlos en lugares apropiados, y así evitar la destrucción o la utilización inapropiada de los mismos.

Es importante que la Universidad Estatal de Bolívar, como forjadora de la educación superior, asigne presupuesto para la conformación de un museo de rastros arqueológicos, la creación de una carrera en Ciencias Sociales y el Departamento de Historia y formar parte de la Academia Nacional de Historia del país, con el fin de impulsar el conocimiento de nuestras culturas ancestrales y conservar los hallazgos como una riqueza inmensurable para los bolivarenses.

Es oportuno proponer un levantamiento de los sitios prehispánicos, por parte de profesionales bolivarenses, a lo largo y ancho de la provincia, para conformar el Atlas Arqueológico de la Provincia, un instrumento valioso para profesores, estudiantes e investigadores del mundo entero. 


\section{Referencias bibliográficas}

Arellano, J. (1992). Asentamientos arqueológicos tardíos del período de integración en la cuenca del río Chimbo. Ecuador. SARANCE. Revista Del Insituto Otavaleño de Antropología, 16, 173-204.

Berdichewsky, B., y de Guzmán, M. (1971). Excavaciones en cementerios indígenas de la región de Calafquén. Universidad de Chile, Departamento de Ciencias Antropológicas y Arqueología.

Calvo, J. (1995). De acá para allá: lenguas y culturas Amerindias. Valencia. España: IVALCA.

Casa de la Cultura Ecuatoriana, Q. (1956). Los Chimbus. Publisher, 1.

Costales, A., y Costales, D. (2002). HUAMBRACUNA. La epopeya de Yahuarcocha (1ra ed.). Quito - Ecuador: ABYAYALA.

Costales. (1954) Los Chimbus. Quito: Instituto Ecuatoriano de Arqueología y Geografía-IEAG, 1954.

Costales Sarmiento, A. (1956). Los Chimbos. Casa de la Cultura Ecuatoriana, 2.

Echeverría, B. (1981) Definición de la cultura: curso de Filosofía y Economía. México: Editorial Itaca.

González Suárez, F. (1890). Historia general de la República del Ecuador. En F. G. Suarez, Historia general de la República del Ecuador (pág. Primer Tomo). Quito : Imprenta del Clero.

Guamán, Y. (2018). Diseño de motivos para bayetas Warankas, inspirados en la flora endémica de la ciudad de Guaranda y difusión en medios gráficos. Escuela Superior Politécnica de Chimborazo.

Itier, C. (2015). "Quechua” y el sistema inca de denominación de las lenguas. Mélanges de La Casa de Velázquez, 45(1), 37-56.

Jijón y Caamaño, J. (1951). El Ecuador Interandino y Occidental antes de la Conquista Castellana. Editorial Ecuatoriana. Quito - Ecuador.

La Condamine, C. (1986). Primera Mision Geodesica. Quito: Coloquio Ecuador.

Millones, L. (2001). Pedro de Cieza de León y su Crónica de Indias. La entrada de los Incas en la Historia Universal (1ra ed.). Perú: IEFA Instituto Francés de Estudios Andinos.

Moreno Yánez, S. (1981): “Colonias mitmas en el Quito incaico: su signifi cación económica y política”. Colección Pendoneros, № 20; pág. 103-127; Otavalo; Instituto Otavaleño de Antropología; 1981.

Paz Maldonado, J. (1889). Relación del pueblo de San Andrés o Xunxi. Relaciones Geofráficas de Indias, Madrid - España. 
Ramón, G (1993). El regreso de los runas: la potencialidad del proyecto indio en el Ecuador contemporáneo. Quito: Comunidec-Fundación Interamericana, 1993.

Vainfas, R. (1996). Debates de la Historia de las Mentalidades a la Historia Cultural. Anuario Colombiano de Historia Social Y de La Cultura, 23, 219-233.

Vásquez de Espinosa, A. (1948): “Compendio y descripción de las Indias Occidentales”; Smithsonian Miscellaneuos Collections; Smithsonian Institution; Washington.

Yánez del Pozo, J. (2003). RUNA YACHAI La socialización infantil y la lógica de la subsistencia entre los pueblos indígenas del Ecuador(1ra ed.). Quito - Ecuador: ABYAYALA. 